\title{
Barriers and supportive factors in certified tobacco cessation counselors in Sweden
}

\author{
Anton J. Landgren', Hans Gilljam²
}

\section{Dear Editor,}

In 2005, Sweden ratified the WHO Framework Convention on Tobacco Control (FCTC). Article 14 highlights the importance of tobacco cessation. In 2005, a national standard for certification of tobacco cessation practitioners was adopted in Sweden and six years later a similar standard, the Gold Standard Program (GSP) was introduced. In 2018 there were 18 approved education centers in Sweden and one GSP-training program.

Results from Swedish and Danish cessation counselors have shown optimistic results regarding tobacco quit rates ${ }^{1,2}$. Others have identified barriers for tobacco cessation in various health-care personnel, including a shortage of tobacco cessation experts to refer the patient to ${ }^{3}$, as well as perceived lack of time for counseling ${ }^{4}$ and training in tobacco cessation ${ }^{5}$. To our knowledge, no previous study has explored the characteristics of Swedish tobacco cessation counselors.

An electronic survey was distributed in April 2018 to those who had been certified from 2006 to April 2018 ( $n=902$ ). The survey involved multiple-choice questions regarding sex, education, current employment, working conditions, and time spent on smoking cessation. The survey was anonymous, and did not involve any patients or sensitive material.

There were 586 (65\%) responders. As shown in Table 1, the overwhelming majority (93.9\%) were women. The dominating occupation was nurse/midwife and $76 \%$ stated being active in tobacco cessation. The majority of respondents $(75.5 \%)$ reported that they spent $0.5-2$ hours per week on tobacco cessation and considered the overall possibilities to conduct tobacco cessation as 'moderate'. Most responders saw 0-2 new patients per month in predominantly individual sessions.

The replies to questions dealing with various aspects of support in the work place ranged from moderate to very good for different variables. Although little time was spent on tobacco cessation, the possibilities to spend time on tobacco cessation was stated as moderate by $39 \%$ of the respondents; thus, there seems to be no major hindering factor for conducting tobacco cessation, as opposed to what has been reported ${ }^{4}$.

In contrast to what has been reported from the tobacco cessation database in Denmark, where most tobacco cessation was conducted in a group setting ${ }^{2}$ according to the GSP program, our respondents reported mostly individual cessation sessions. When stratifying by type of cessation education, all those with solely GSP education $(n=36)$ reported individual cessation sessions, even though group-based interventions are more cost-effective than individual consultations ${ }^{6}$. A reason for the dominance of individual cessation sessions could be a low inflow of patients from primary care, possibly due to the deprioritizing of smoking-related diseases such as chronic obstructive pulmonary disorder ${ }^{7}$.

Our results show that most consultations with Swedish cessation counselors are
AFFILIATION

1 Department of Rheumatology and Inflammation Research, Institute of Medicine, Sahlgrenska Academy, University of Gothenburg, Gothenburg, Sweden 2 Department of Public Health Sciences, Karolinska Institute, Stockholm, Sweden

CORRESPONDENCE TO Anton Jonatan Landgren. Department of Rheumatology and Inflammation Research, Institute of Medicine, Sahlgrenska Academy, University of Gothenburg, Gothenburg, Sweden. E-mail: anton.landgren@rheuma. gu.se ORCID ID: https://orcid. org/0000-0001-7922-3335

KEYWORDS

survey, education, activity, occupation, tobacco cessation

Received: 14 November 2018 Revised: 13 January 2019 Accepted: 17 January 2019 
on an individual basis. We also found that little time is spent on tobacco cessation, despite that more than $50 \%$ consider their 'overall possibilities to conduct tobacco cessation' as moderate. Further studies are warranted to examine the reasons behind the short time spent on tobacco cessation and how more patients in need could benefit from this treatment.

Table 1. Characteristics of tobacco cessation counselors (Total $\mathrm{N}=586$ )

\begin{tabular}{|c|c|c|c|}
\hline Characteristics & n $(\%)$ & Characteristics & $n(\%)$ \\
\hline $\operatorname{Sex}(n=586)$ & & Yes, active & $434(76.0)$ \\
\hline Male & $36(6.1)$ & No demand & $38(6.7)$ \\
\hline Female & 550 (93.9) & No, new job & $48(8.4)$ \\
\hline Education $(n=586)$ & & No, service stopped & $13(2.2)$ \\
\hline Nurse, midwife & $415(70.8)$ & No, other reason & $36(6.3)$ \\
\hline Psychologist & $1(0.2)$ & Retired & $2(0.3)$ \\
\hline Dental hygienist & $31(5.3)$ & Doctor's readiness to prescribe $(n=484)$ & \\
\hline Dentist & $0(0)$ & Easy & $354(73.1)$ \\
\hline Public health practicioner & $23(3.9)$ & Varies between different physicians & $109(22.5)$ \\
\hline Physician & $2(0.3)$ & Resistance & $21(4.3)$ \\
\hline Other & $114(19.5)$ & Hours per week spent on cessation $(n=458)$ & \\
\hline Current position $(n=584)$ & & $0.5-2$ & $346(75.5)$ \\
\hline Nurse, midwife & $386(66.1)$ & $2.5-5$ & $74(16.1)$ \\
\hline Psychologist & $1(0.2)$ & $5.5-10$ & $18(3.9)$ \\
\hline Dental hygienist & $31(5.3)$ & $>10.5$ & $20(4.4)$ \\
\hline Dentist & $0(0.0)$ & New patients per month $(n=462)$ & \\
\hline Mainly cessation counselor & $36(6.2)$ & $0-2$ & $288(62.3)$ \\
\hline Physician & $2(0.3)$ & $3-4$ & $111(24.0)$ \\
\hline Other & $128(21.9)$ & $5-6$ & $35(7.6)$ \\
\hline Work place $(n=585)$ & & $7-10$ & $11(2.4)$ \\
\hline Primary care public & $285(48.6)$ & $>10$ & $17(3.7)$ \\
\hline Primary care private & $106(18.1)$ & Group vs individual cessation $(n=467)$ & \\
\hline Hospital & $85(14.5)$ & Individual & $435(93.1)$ \\
\hline Occupational health care & $19(3.2)$ & Group & $32(6.9)$ \\
\hline Other health care center & $37(6.3)$ & Follow-up $(n=468)$ & \\
\hline Other & $53(9.0)$ & Face-to-face & $208(44.4)$ \\
\hline Type of cessation education $(n=586)$ & & Telephone & $223(47.6)$ \\
\hline Diploma D & $486(82.9)$ & No system & $14(3.0)$ \\
\hline GSP & $36(6.1)$ & Other & $23(4.9)$ \\
\hline Diploma D + GSP & $18(3.1)$ & Cessation in workplace $(n=483)$ & \\
\hline Other & $46(7.8)$ & I work alone & $261(54.0)$ \\
\hline Year of diploma training $(n=586)$ & & I work in a team & $222(46.0)$ \\
\hline Before 2005 & $25(4.3)$ & Management of patient information $(n=473)$ & \\
\hline 2005-2008 & $45(7.7)$ & Registering in the clinic's own system & $450(95.1)$ \\
\hline 2009-2012 & $92(15.7)$ & Registering in own computerized system & $11(2.3)$ \\
\hline 2013-2016 & $269(45.9)$ & Registering on paper & $12(2.5)$ \\
\hline 2017-2018 & $155(26.5)$ & Referal routines $(n=452)$ & \\
\hline Active in cessation $(n=571)$ & & I get written referrals and replies & $195(43.1)$ \\
\hline
\end{tabular}


Table 1. Continued

Charracteristics
No routines for referrals or replies
Support from manager $(\mathrm{n}=558)$
Very good
Moderate
Small/none
Bad
Support from administrative personnel ( $\mathrm{n}=554)$
Very good
Moderate
Small/none
Bad
Possibilities to affect work environment ( $\mathrm{n}=558)$
Very good
Moderate
Small/none
Bad
Possibilities to spend time on cessation ( $\mathrm{n}=551)$
Very good
Moderate
Small/none
Bad
Possibilities for continuing cessation education
( $=553$ )

Table 1. Continued

\begin{tabular}{lc} 
Characteristics & n (\%) \\
Very good & $82(14.8)$ \\
Moderate & $254(45.9)$ \\
Small/none & $50(9.0)$ \\
Bad & $167(30.2)$ \\
Overall possibilities to conduct cessation ( $\mathrm{n}=549)$ & \\
Very good & $117(21.3)$ \\
Moderate & $301(54.8)$ \\
Small/none & $36(6.6)$ \\
Bad & $95(17.3)$ \\
Knowledge about guidelines ( $\mathrm{n}=518)$ & \\
Yes, we adhere to guidelines & $279(53.9)$ \\
Known, but not always practiced & $157(30.3)$ \\
Known only by the cessationers & $38(7.3)$ \\
Mostly unknown & $44(8.5)$ \\
Where do your patients come from? (n=471) & \\
Many different caregivers (hospital, primary care, & \\
other) & $137(29.1)$ \\
Only or almost only from own caregiver & $334(70.9)$ \\
Is it important for you that the survey is & \\
anonymous? ( $\mathrm{n}=586)$ & $196(28.3)$ \\
No & \\
Yes & \\
No opinion & \\
a Prescription of replacement therapy, varenicline and bupropion. & \\
& \\
\hline
\end{tabular}

\section{REFERENCES}

1. Helgason AR, Tomson T, Lund KE, Galanti R, Ahnve S, Gilljam H. Factors related to abstinence in a telephone helpline for smoking cessation. European journal of public health. 2004;14(3):306-310. doi:10.1093/eurpub/14.3.306

2. Rasmussen M, Fernandez E, Tonnesen H. Effectiveness of the Gold Standard Programme compared with other smoking cessation interventions in Denmark: a cohort study. BMJ open. 2017;7(2):e013553. doi:10.1136/bmjopen-2016-013553

3. Helgason AR, Lund KE. General practitioners' perceived barriers to smoking cessation-results from four Nordic countries. Scandinavian journal of public health. 2002;30(2):141-147. doi:10.1080/14034940210133799

4. Naughton F, Hopewell S, Sinclair L, McCaughan D, McKell J, Bauld L. Barriers and facilitators to smoking cessation in pregnancy and in the post-partum period: The health care professionals' perspective. British journal of health psychology. 2018;23(3):741-757. doi:10.1111/bjhp.12314

5. Abatemarco DJ, Steinberg MB, Delnevo CD. Midwives' knowledge, perceptions, beliefs, and practice supports regarding tobacco dependence treatment. Journal of midwifery \& women's health. 2007;52(5):451-457. doi:10.1016/j.jmwh.2007.03.019

6. Bauld L, Chesterman J, Ferguson J, Judge K. A comparison of the effectiveness of group-based and pharmacy-led smoking cessation treatment in Glasgow. Addiction. 2009;104(2):308-316. doi:10.1111/j.1360-0443.2008.02446.x

7. Sandelowsky H, Hylander I, Krakau I, Modin S, Stallberg B, Nager A. Time pressured deprioritization of COPD in primary care: a qualitative study. Scandinavian journal of primary health care. 2016;34(1):55-65. doi:10.3109/02813432.2015.1132892

CONFLICTS OF INTEREST

The authors have completed and submitted the ICMJE Form for Disclosure of Potential Conflicts of Interest and none was reported.

\section{FUNDING}

This project was supported by the National Board of Health and Welfare.

PROVENANCE AND PEER REVIEW

Not commissioned; externally peer reviewed 